\title{
Toxicity of Weight Loss Agents
}

\author{
May Yen • Michele Burns Ewald
}

Published online: 14 February 2012

(C) American College of Medical Toxicology 2012

\begin{abstract}
Introduction: With the rise of the obesity epidemic in the United States over the last several decades and the medical complications seen with it, weight loss and dieting have become a national public health concern. Discussion: Because of their increased use and availability through internet sales, several different dieting agents were reviewed for potential toxicity. These included: syrup of ipecac, cathartics, human chorionic gonadotropin hormone, 2,4 Dinitrophenol, guar gum, phenylpropanolamine, ma huang/ ephedra, caffeine, clenbuterol, fenfluramine, sibutramine, thyroid hormone, orlistat and cannabinoid antagonists. Conclusions: With the internet making even banned products readily accessible, healthcare providers need to be aware of the potential toxicities of a wide range of weight loss agents. Our review covered topics we thought to be most historically significant as well as pertinent to the practice of medical toxicology today.
\end{abstract}

\section{Keywords Weight loss agent toxicity · Diet agent toxicity}

\section{Introduction}

Globally, there are an estimated 937 million overweight adults; currently, the USA claims the largest population of overweight and obese individuals [1]. In 2008, the National Health and Nutrition Examination Survey (NHANES) estimated that $33.8 \%$ of adults and $16.9 \%$ of children and adolescents aged 2-19 were obese while $68.0 \%$ of adults and $31.7 \%$ of youths were found to be either overweight or obese. Obesity in adults is defined as a body mass index (BMI) of 30 or higher and overweight is defined as a BMI of 25.0-29.9. In children, obesity is determined by weight

M. Yen $(\bowtie) \cdot$ M. B. Ewald

Children's Hospital Boston, Harvard Medical Toxicology

Fellowship,

300 Longwood Ave, Ida C. Smith Building,

Boston, MA 02115, USA

e-mail: May.Yen@childrens.harvard.edu percentiles on the growth curve with those pediatric patients above the 95th percentile considered obese and those above the 85th percentile overweight [2].

Dieting behaviors have become widespread among both adults and teenagers in the USA. In 2010 Marketdata Enterprises estimated that 75 million US dieters spent nearly \$US 61 billion on weight loss products [3]. Surveys have shown that $37 \%$ of children in grades 3-6 have already tried to lose weight with $6.9 \%$ having demonstrated dieting to the extreme. Approximately $70 \%$ have described themselves as "fat" and $45 \%$ have desired to be thinner [4]. Another study suggests that the early development of disordered eating is likely to set the stage for ongoing issues into young adulthood [5].

Overweight adolescents and adults are more likely to use unhealthy weight management strategies (i.e., diet pills and laxatives) as opposed to engaging in healthier strategies [6]. Since passage of the Dietary Supplement and Health Education Act (DHSEA) in 1994, the FDA is restricted in their ability to regulate dietary supplements [7]. In this review article, we discuss the toxicities of different weight loss agents; a PubMed search for articles from 1935 to 2011 was performed and the articles thought most pertinent to the practice of medical toxicology were included. With the internet making even banned products readily accessible, healthcare providers need to be aware of the potential toxicities of both historically significant as well as currently sold products.

\section{Ipecac}

Syrup of ipecac was frequently utilized in the past by healthcare providers as a decontamination measure for gastric emptying after ingestion of a potentially toxic agent. The US Food and Drug Administration (FDA) first approved ipecac syrup for over-the-counter sale in 1965. Initially, both poison centers and pediatricians widely advocated its use; more recently, given its potential toxic effects with limited 
efficacy, it is no longer recommended by the American Academy of Pediatrics (AAP) since 2003 [8]. While the Toxic Exposure Surveillance System (TESS) reported 13,555 uses of ipecac for decontamination in 2002, and the National Poison Data System (NPDS) reported 163 uses in 2010 , no recent epidemiologic information is available regarding ipecac abuse for weight loss [9].

Ipecac is derived from dried roots and rhizomes of the Cephaline ipecacuanha plant; its chief pharmacologic properties are due to its alkaloid components, emetine and cephaline. Of the two alkaloids, emetine is found to be the more cardiotoxic and constitutes more than half of the alkaloid content of ipecac. Vomiting is induced peripherally through stimulation of the gastric mucosal sensory receptor and centrally by chemoreceptor trigger zone activation. A toxic dose of emetine was seen in as little as $1.25 \mathrm{~g}$ (approximately ten times the therapeutic dose); emetine's damage is related to cumulative exposure [10]. Historically, ipecac has been used to treat amebiasis and is still used today in child medical maltreatment as well as by patients with the eating disorder bulimia nervosa.

Multiple complications have been seen with the acute use of ipecac including case reports of aspiration [11], MalloryWeiss tears [12], pneumomediastinum [13], and intracerebral hemorrhage [14]. A reversible myopathy has also been observed in multiple cases $[10,15-17]$ associated with chronic ipecac use, as seen in bulimics. The most toxic effects are generally related to the cardiovascular system; symptoms include precordial chest pain, tachycardia, dyspnea, and hypotension [16]. ECG findings associated with chronic ipecac abuse include flattening and inversion of $\mathrm{T}$ waves and prolongation of the QTc interval, premature atrial complexes, ventricular arrhythmias, and PR interval prolongation $[15,18$, 19]. The pathogenesis of cardiac toxicity is unclear; interstitial edema, separation of muscle fibers, increased eosinophilia of the sarcoplasm, loss of striation, and focal muscle necrosis have been seen histologically [10]. Given the reversible nature of the cardiomyopathy, general supportive care and removal from exposure is recommended. However, death can occur secondary to heart failure and cardiac arrest. Karen Carpenter, a popular US singer who performed regularly in the 1970s, died of ipecac-induced cardiac disease [16].

\section{Laxatives}

Laxatives and diuretics can result in electrolyte abnormalities. Potassium, chloride, and hydrogen ions are often lost in the vomitus which results in metabolic alkalosis and hypokalemia. Laxative abuse is more commonly seen in bulimics than ipecac abuse. Lifetime occurrence of laxative abuse has been reported to be $4.18 \%$ in the general population and $14.9 \%$ in individuals with bulimia nervosa. Other studies had found laxative abuse in $75 \%$ of patients with bulimia nervosa [20]. There are multiple types including bulk laxatives, fecal softeners, stimulant laxatives, and osmotic laxatives. Medical complications associated with laxatives include chronic diarrhea which disrupts the normal stool electrolyte concentrations that then leads to serum electrolyte shifts; acutely, hypokalemia is most typically seen. Severe hypokalemia has also been associated with distal renal tubular acidosis. Two additional gastrointestinal manifestations of chronic laxative abuse are Melanosis Coli and cathartic colon. Melanosis coli is a benign discoloration of the colonic mucosa which is often secondary to chronic use of anthraquinone-containing laxatives. Cathartic colon results from stimulant laxative use. The large intestine suffers nerve damage from the chronic laxative use that renders it unable to function properly. The normal peristalsis and conduction is affected; the disorder is thought to be secondary to a degeneration of Auerbach's plexi [20, 21]. Treatment is mainly supportive care with electrolyte repletion and discontinuation of the agents.

\section{Human Chorionic Gonadotrophin (HCG) Hormone}

Low-dose HCG injections, combined with a low-calorie diet, are a more novel treatment approach for obesity; this diet averages 500 calories a day. Simeons first proposed this therapy after observation of the use of HCG in pregnant women as well as for the treatment of Frolich's syndrome (a condition in males with hypothalamic and pituitary tumors, obesity, and hypogonadism). It was noted that HCG administration appeared to diminish and change fat distribution $[22,23]$. The theory is that HCG causes the body to preferentially burn stored fat, allowing patients to then lose more weight than a restrictive diet alone. In addition, HCG is purported to suppress the appetite and allow patients to tolerate a restrictive diet without severe hunger. Reported acute adverse effects include mild hypotension, hypoglycemia, constipation, and fatigue [23]. There is also a theoretical concern of increased thrombosis risk with IM injections of HCG [24]. However, there has been a paucity of evidence for this dietary agent with multiple studies showing that weight loss was generally related to diet restriction as opposed to HCG injections [23, 25, 26].

\section{2,4 Dinitrophenol}

Dinitrophenol (DNP) has been used historically in dyes, wool preservatives, herbicides, and explosives since the 1930s. DNP causes uncoupling of mitochondrial oxidative phosphorylation that leads to increased fat metabolism with subsequent weight loss. The danger of DNP lies in the 
mechanism of action; uncoupling of oxidative phosphorylation, as in aspirin toxicity, leads to an accumulation of pyruvic and lactic acids as well as an inhibition of ATP formation which is then dissipated as heat. Acute toxicity presents with hyperthermia, tachycardia, diaphoresis, tachypnea, and cardiac arrest; morbidity often occurs with severe hyperthermia. Treatment is supportive with an emphasis on aggressive cooling measures. DNP was first criticized in the mid-1930s after multiple cases of cataracts were found to be associated with its use [27]. DNP has not been legally prescribed since being banned in 1938; however, there have been continued case reports of its use $[28,29]$. With the internet providing access to DNP, there have been increased reports of its use over the last decade [30], including multiple reports of fatalities [28, 29, 31, 32]. Particular notoriety was brought to the drug in the 1980s when a Texan physician who privately processed DNP and marketed it as 'Mitcal;' his widespread distribution eventually resulted in a death in 1984 and his conviction in 1986 [30].

\section{Guar Gum}

Guar gum comes from a legume crop that is found mostly in India and Pakistan and is used primarily as a food thickener. Today, it can be easily obtained through internet sales. Considered a dietary fiber, guar gum has been used to lower cholesterol levels from the enhanced excretion of bile acids into feces and a decreased absorption of dietary lipids [33]. Weight loss may be achieved by the increased fecal excretion of lipids as well as through promoting a feeling of fullness and early satiety resulting in decreased caloric intake. The feeling of fullness is thought to be secondary to delayed gastric emptying. Acute potential adverse events include abdominal pain, flatulence, diarrhea, and cramps [34]; there have also been multiple reports of esophageal and small bowel obstructions. Although a predisposing gastric disorder was present in roughly half of the reported cases, there have been a significant number of cases without any reported risk factors [35]. In addition, a recent metaanalysis of randomized trials looking at guar gum use for weight loss reduction did not find significant efficacy [34]. Treatment is primarily supportive with urgent surgical consultation for abdominal obstruction.

\section{Phenylpropanolamine}

Phenylpropanolamine (PPA) is a synthetic sympathomimetic amine; it is structurally and functionally similar to amphetamine and ephedrine. It was formerly widely available in multiple over-the-counter medications such as cough and cold preparations as well as in appetite suppressants. In 1999, TESS reported
1305 cases related to PPA use in diet aids. Despite being banned in 2000, the 2010 NPDS reported 42 cases of use in diet aids and over 500 cases of use with decongestants or analgesics [9]. PPA is primarily a selective agonist at the alpha-adrenergic receptor as well as a catecholamine reuptake inhibitor. Action is also seen at the beta receptor and in the CNS; the CNS stimulation is thought to be responsible for its anorectic effects leading to its use in diet pills [36]. Adverse effects of the medication include headache, tremor, insomnia, agitation, chest pain with significant toxicity producing palpitations, and severe hypertension [37]. Use of PPA has been associated with hemorrhagic strokes, cerebral vasculitis as well as infarctions; it is thought to be an independent risk factor for hemorrhagic stroke in women $[36,38]$. In addition, multiple cases of myocardial infarction have been also been associated with hypertensive episodes from use of PPA without any significant risk factors [39, 40]. In 2000, Kernan et al. [38, 41] linked the use of PPA with a risk of hemorrhagic stroke, and thus the FDA issued a public health warning and mandated that all companies remove PPA from their over-the-counter products. Treatment of symptoms associated with the use of PPA focuses on blood pressure control with an alpha blocking agent or a direct acting vasodilator.

\section{Ma Huang/Ephedra}

Ma Huang, also known as Ephedra, is a dietary supplement that is comprised of ephedra alkaloids and guarana-derived caffeine. It has been used medicinally in China for thousands of years [42] and is marketed in the USA as an energy booster and weight control agent through its agonism of adrenergic receptors [43]. Treatment is supportive with symptomatic control of the patient's adrenergic state. In April of 2004, the FDA banned the sale of Ma Huang/ephedra in the USA [45]; however, it continues to be available over the internet and abroad. Prior to being banned, there were 8034 cases reported by TESS in 2003; in 2010, there were only 348 cases reported to NPDS [9]. Toxicity includes acute myocardial infarction, hypertension, cardiac dysrhythmias, as well as hemorrhagic and ischemic strokes [44, 46, 47]. The adrenergic effects of Ma Huang/ephedra result in shortened cardiac refractory periods which then lead to cardiac arrhythmias, myocardial infarction, and sudden death [47]; this phenomenon has been seen in patients without any underlying cardiovascular disease [48].

\section{Caffeine}

Caffeine is not only found in widely consumed drinks such coffee, tea, soft, and energy drinks but also often present in 
many products that contain ephedra alkaloids as well as in appetite suppressants. Recently the Drug Abuse Warning Network (DAWN) reported an increase in caffeine-related emergency room visits from 1,128 in 2005 to 13,114 visits in 2009 [49]. As a methylated xanthine, it is structurally similar to theophylline; it stimulates the CNS as well as the myocardium and skeletal muscles. Caffeine, in moderate doses, has direct antagonism at the adenosine receptors; in higher doses it has both phosphodiesterase inhibition as well as prostaglandin inhibition. It further acts by central vasoconstriction and augmentation of catecholamine release. Acutely toxic patients present with symptoms of nausea, vomiting, tachycardia, opisthotonos, myoclonic jerks, seizures, and cerebral edema. The most common electrolyte abnormalities are hypokalemia, hypocalcemia, and hyperglycemia [50]. There have been multiple reports of fatalities following massive ingestions of caffeine [51], generally secondary to ventricular arrhythmias. Toxic effects have been seen with doses of $15 \mathrm{mg} / \mathrm{kg}$ with fatalities seen in ingestions greater than $150 \mathrm{mg} / \mathrm{kg}$ [52]. In addition, one must be cognizant of combination preparations of caffeine with other toxic agents including salicylates in dietary agents [53]. Treatment includes aggressive electrolyte repletion, consideration of antiarrhythmics for ventricular arrhythmias, and hemodialysis for refractory cases.

\section{Clenbuterol}

Clenbuterol is a long acting beta- 2 adrenergic agonist with a reported half-life of up to $39 \mathrm{~h}$. In recent years, it has been found as an additive or adulterant of certain street drugs, mostly in heroin [54]. In the 2010 annual report from the NPDS, no specific reports of clenbuterol were described; however it does list greater than 2500 cases of "other beta-2 agonist" cases [9]. Outside the USA, it has been frequently used as a bronchodilator in the treatment of asthma for both humans and horses [55]. In addition, it has specific anabolic activity and increased lipolysis that is not seen with other beta agonists. Abuse is often observed in the setting of livestock development and bodybuilding in order to increase lean muscle [56, 57]. Acute clenbuterol toxicity presents with tachycardia, tachyarrhythmias, palpitations, anxiety, tremor, and shortness of breath; hypokalemia is often seen with its use as well. Treatment is through electrolyte repletion, supportive care, and use of beta antagonists.

\section{Fenfluramine/Serotonergic Agents}

Fenfluramine is a sympathomimetic amine that was often used in combination with phentermine (known colloquially as Fen-Phen ${ }^{\circledR}$ ) as a weight control measure. Its popularity rose in the 1980s and $1990 \mathrm{~s}$; in 1996 over 18 million prescriptions were written for fenfluramine and phentermine [58]. Fenfluramine's action is mediated through serotonergic pathways; it both promotes the release and inhibits the reuptake of serotonin. Dexfenfluramine, the d-isomer of fenfluramine, was also utilized in weight loss products because of its CNS selectivity. Phentermine is an amphetamine derivative that directly stimulates the sympathomimetic pathway. In the mid-1990s, physicians at the Mayo Clinic became aware of possible cardiac ramifications after seeing 24 young women present with new onset valvular disease after initiation of Fen-Phen ${ }^{\circledR}$. Thickening of the heart valves, most often aortic and mitral, was seen along with thickening and shortening of the chordae tendineae, with subsequent valvular regurgitation $[58,59]$ after chronic use. In addition, primary pulmonary hypertension has also been linked to chronic fenfluramine use; the absolute risk was 30 times greater in people using anorectic agents for greater than 3 months [60]. While the pathophysiology is not clear, it is thought that serotonin acts as a vascocontrictor [61]. Flenfluramine and the combination Fen-Phen ${ }^{\circledR}$ was officially withdrawn in 1997 following Connolly et al's publication of valvular abnormalities in relation to its use.

Sibutramine is a combined norepinephrine and serotonin reuptake inhibitor that was prescribed as an anti-obesity agent. It has a peripheral sympathomimetic effect that results in an increased heart rate and a moderate rise in blood pressure; sibutramine also induces satiety and increases energy expenditure [62]. Specifically prescribed for clinically obese patients, it had initially demonstrated, through reassuring initial studies, a safe drug profile [63]. However, isolated case reports started appearing that cited mania, panic attacks and psychosis as side effects of the medication [64]. In addition, a recent study demonstrated, at 5-year follow-up, a significant increased risk of nonfatal myocardial infarction and nonfatal stroke in patients with preexisting cardiovascular conditions [65]. In October of 2010 , the FDA officially recalled the medication.

\section{Thyroid Hormone}

The NPDS annual report for 2010 lists over 13,000 calls related to thyroid preparations, although it is unclear how many of these calls were taken as intentional ingestions [9]. The actions of thyroid hormone both centrally at the hypothalamus, as well as its peripheral effects, are responsible for the increased basal metabolic rate. Hyperthyroidism is associated with weight loss through an increased metabolic rate. Exogenous thyroid hormone use has been associated with episodes of thyroid storm as well as thyrotoxic periodic paralysis [66, 67]. Thyrotoxic periodic paralysis is an acute complication of thyrotoxicosis and often seen in those of Asian descent [68]. It presents with 
marked proximal muscle weakness in both upper and lower limbs, hypokalemia and signs of hyperthyroidism; one case describes a 21-year-old male with an initial serum potassium concentration of $1.2 \mathrm{meq} / 1$. Hyperthyroidism generally presents with tachycardia, hypertension, hyperthermia, and cardiac arrhythmias $[69,70]$. There have been case reports of death secondary to thyroid storm after intentional intake of thyroid hormone as a weight control measure [70]. Treatment of toxicity follows the mainstay of thyroid storm therapy with beta-blockade, cooling measures, and electrolyte repletion.

\section{Orlistat}

Orlistat is a lipase inhibitor that acts locally in the GI tract; pancreatic and gastric lipases are the key enzymes involved in

Table 1 Weight loss agents

\begin{tabular}{|c|c|c|}
\hline Agent & Mechanism of Action & Toxicity \\
\hline \multirow[t]{4}{*}{ Ipecac } & Activation of central chemoreceptor trigger zone & Aspiration \\
\hline & Stimulation of gastric mucosa & Mallory-Weiss tears \\
\hline & & Pneumomediastinum \\
\hline & & Cardiomyopathy (chronic abuse) \\
\hline \multirow[t]{3}{*}{ Laxatives } & Electrolyte shifts & Hypokalemia \\
\hline & & Melanosis coli \\
\hline & & Cathartic colon \\
\hline \multirow[t]{3}{*}{ Human Chorionic Gonadotropin (HCG) } & Low calorie diet & Hypoglycemia \\
\hline & Preferentially burns fat Stores & Hypotension \\
\hline & & Constipation \\
\hline \multirow[t]{3}{*}{ 2,4-Dinitrophenol (DNP) } & Uncoupler of oxidative phosphorylation & Hyperthermia \\
\hline & & Cataracts \\
\hline & & Tachycardia/cardiac arrest \\
\hline Guar gum & Increased fecal excretion and early satiety sensation & Bowel obstruction \\
\hline \multirow[t]{3}{*}{ Phenylpropanolamine (PPA) } & Sympathomimetic agonist & Hemorrhagic/ischemic strokes \\
\hline & & Myocardial infarction \\
\hline & & Hypertensive crisis \\
\hline \multirow[t]{3}{*}{ Ma Huang/Ephedra } & Sympathomimetic agonist & Myocardial infarction \\
\hline & & Cardiac arrhythmias; sudden death \\
\hline & & Cerebrovascular accident \\
\hline \multirow[t]{4}{*}{ Caffeine } & Adenosine antagonist & Nausea/vomiting \\
\hline & Phosphodiesterase inhibitor & Hypokalemia \\
\hline & CNS stimulant & Ventricular arrhythmias \\
\hline & & Seizures \\
\hline \multirow[t]{2}{*}{ Clenbuterol } & Beta 2 agonist & Tachyarrhythmias \\
\hline & & Hypokalemia \\
\hline \multirow[t]{3}{*}{ 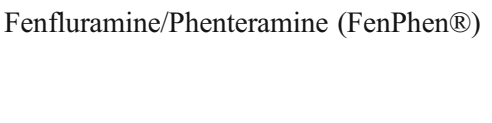 } & Inhibit serotonin reuptake & Valvular disease \\
\hline & Promote serotonin release & Primary pulmonary hypertension \\
\hline & Sympathomimetic agonist & \\
\hline \multirow[t]{3}{*}{ Sibutramine } & Norepinephrine and serotonin reuptake inhibitor & Mania/panic attacks/psychosis \\
\hline & & Myocardial infarction \\
\hline & & Cerebrovascular accident \\
\hline
\end{tabular}


Table 1 (continued)

\begin{tabular}{lll}
\hline Agent & Mechanism of Action & Toxicity \\
\hline Thyroid Hormone & Increased metabolism & $\begin{array}{l}\text { Thyroid storm } \\
\text { Thyrotoxic periodic paralysis }\end{array}$ \\
Orlistat & Lipase inhibitor & Hepatotoxicity \\
& & Incontinence, flatus, oily discharge \\
Cannabinoid Antagonists & Cannabinoid receptor antagonist & Nasopharyngitis \\
& Decrease food intake & Anxiety/depression \\
\end{tabular}

triglyceride hydrolysis which is an essential step for absorption of fats [64]. Although initially a prescription medication, it is now readily available as an over-the-counter diet aid. Reported acute adverse effects of the medication include fecal incontinence, flatus, oily discharge, oily evacuation, and soft stools. There have also been some case reports of a range of hepatotoxicities (cholelithiasis, cholestatic hepatitis, and subacute liver failure), although precise temporal relationships to chronicity of use have not been established [71, 72]. Additional oral supplemental vitamins are required due to orlistat's effect on fat-soluble vitamins [73]. Supportive care and cessation of therapy is recommended if adverse effects occur.

\section{Cannabinoid Antagonists}

The endocannabinoid system regulates energy homeostasis through G-protein coupled cannabinoid-1 receptors. Exogenous cannabinoids and endocannabinoids both increase food intake and promote weight gain by activating central endocannabinoid receptors. Blockade of cannabinoid type 1 receptor (CB-1) is thought to reduce body weight. CB-1 is found both in the brain and peripheral tissues including adipose tissue, muscle, the GI tract, and liver. Rimonabant specifically blocks the CB-1 receptor to reduce food intake and results in weight loss through its action at central and peripheral systems [74]. Acute adverse events include upper respiratory infections, nasopharyngitis, nausea, anxiety, depression, fatigue, and dizziness. Although a recent randomized controlled trial noted significant reduction in weight, waist circumference, and lipid studies in patients taking rimonabant, there was a high drop-out rate in its participants due to the above toxicities [75]. The FDA never approved this drug in the USA, and as of 2009 the European Medicines Agency (EMEA) suspended it from the European continent. Treatment of adverse effects is mainly through supportive care, symptomatic control, and cessation of therapy.

\section{Discussion}

With the rise of the obesity epidemic in the USA and the medical complications seen with it, weight loss and dieting have become a national concern. Weight loss agents work through three distinct mechanisms: (1) anorectic function via appetite suppression, (2) alteration of food absorption or excretion, and (3) increased energy expenditure. Of greatest concern are agents that fall under the third category as these are the products associated with the highest mortality and morbidity.

Weight loss agents should be considered with an undifferentiated poisoned patient (see Table 1). Patients who present with a sympathomimetic state may be poisoned with DNP, PPA, ephedra, thyroid hormone, Fen-Phen ${ }^{\circledR}$, sibutramine, caffeine/methylxanthines, or clenbuterol. In particular, cardiac abnormalities, dysrhythmias and sudden death are of greatest concern. Hemorrhagic strokes and CVAs are also often seen with these same agents. Certain agents, such as caffeine/methylxanthines and clenbuterol, are often seen with marked hypokalemia, nausea/vomiting, and tachyarrythmias. Patient who abuse ipecac and cathartics may also present with electrolyte abnormalities including hypokalemia. Agents that alter food absorption/excretion such as guar gum and orlistat should be kept in mind with complaints of abdominal pain, obstruction and hepatotoxicity of unknown etiology. Otherwise, nonspecific symptoms such as fatigue, upper respiratory symptoms, and constipation have been seen in anorectic agents such as HCG injections and endocannabinoid blockers.

\section{Conclusions}

With the internet making even banned products readily accessible, healthcare providers need to be aware of the potential toxicities of a wide range of weight loss agents. Our review covered topics we thought to be most historically significant as well as pertinent to the practice of medical toxicology today. 


\section{References}

1. Shao Q, Chin K-V (2011) Survey of American food trends and the growing obesity epidemic. Nutr Res Pract 5(3):253-259

2. Flegal KM, Carroll MD, Ogden CL, Curtin LR (2010) Prevalence and trends in obesity among US adults, 1999-2008. JAMA 303 (3):235-241

3. Anon. The U.S. weight loss and diet control market, 11th edn.) by Marketdata Enterprises in Diet food and weight loss, Healthy, United States. Available at: http://www.marketresearch.com/ Marketdata-Enterprises-Inc-v416/Weight-Loss-Diet-Control-11th6314539/. Accessed October 31, 2011

4. Maloney MJ, McGuire J, Daniels SR, Specker B (1989) Dieting behavior and eating attitudes in children. Pediatrics 84(3):482-489

5. Neumark-Sztainer D, Wall M, Larson NI, Eisenberg ME, Loth K (2011) Dieting and disordered eating behaviors from adolescence to young adulthood: findings from a 10 -year longitudinal study. J Am Diet Assoc 111(7):1004-1011

6. Boutelle K, Neumark-Sztainer D, Story M, Resnick M (2002) Weight control behaviors among obese, overweight, and nonoverweight adolescents. J Pediatr Psychol 27(6):531-540

7. Anon. Chapter I - Dietary supplement health and education act of 1994. Available at: http://www.health.gov/dietsupp/ch1.htm. Accessed October 31, 2011

8. Anon (2003) Poison treatment in the home. American Academy of Pediatrics Committee on injury, violence, and poison prevention. Pediatrics 112(5):1182-1185

9. Bronstein AC, Spyker DA, Cantilena LR et al (2011) 2010 Annual Report of the American Association of Poison Control Centers' National Poison Data System (NPDS): 28th Annual Report. Clin Toxicol (Phila) 49(10):910-941

10. Schiff RJ, Wurzel CL, Brunson SC et al (1986) Death due to chronic syrup of ipecac use in a patient with bulimia. Pediatrics 78(3):412-416

11. Wrenn K, Rodewald L, Dockstader L (1993) Potential misuse of ipecac. Ann Emerg Med 22(9):1408-1412

12. Tandberg D, Liechty EJ, Fishbein D (1981) Mallory-Weiss syndrome: an unusual complication of ipecac-induced emesis. Ann Emerg Med 10(10):521-523

13. Wolowodiuk OJ, McMicken DB, O’Brien P (1984) Pneumomediastinum and retropneumoperitoneum: an unusual complication of syrup-of-ipecac-induced emesis. Ann Emerg Med 13(12):11481151

14. Klein-Schwartz W, Gorman RL, Oderda GM, Wedin GP, Saggar D (1984) Ipecac use in the elderly: the unanswered question. Ann Emerg Med 13(12):1152-1154

15. Ho PC, Dweik R, Cohen MC (1998) Rapidly reversible cardiomyopathy associated with chronic ipecac ingestion. Clin Cardiol 21 (10):780-783

16. Palmer EP, Guay AT (1985) Reversible myopathy secondary to abuse of ipecac in patients with major eating disorders. N Engl J Med 313(23):1457-1459

17. Brotman MC, Forbath N, Garfinkel PE, Humphrey JG (1981) Myopathy due to ipecac syrup poisoning in a patient with anorexia nervosa. Can Med Assoc J 125(5):453-454

18. Cera LJ (1956) Emetine toxicity with electrocardiographic abnormalities. Circulation 14(1):33-37

19. Turner PP (1963) The effects of emetine on the myocardium. Br Heart J 25:81-88

20. Roerig JL, Steffen KJ, Mitchell JE, Zunker C (2010) Laxative abuse: epidemiology, diagnosis and management. Drugs 70(12): $1487-1503$

21. Harris RT (1983) Bulimarexia and related serious eating disorders with medical complications. Ann Intern Med 99(6):800-807
22. Simeons AT (1954) The action of chorionic gonadotrophin in the obese. Lancet 267(6845):946-947

23. Stein MR, Julis RE, Peck CC et al (1976) Ineffectiveness of human chorionic gonadotropin in weight reduction: a double-blind study. Am J Clin Nutr 29(9):940-948

24. Cunningham E (2010) Where can I find information on the use of human chorionic gonadotrophin (HCG) for weight loss? J Am Diet Assoc 110(12): 1960

25. Rabe T, Richter S, Kiesel L, Zaloumis M, Runnebaum B (1987) Influence of human chorionic gonadotropin (hCG) in combination with a 500 calorie diet on clinical and laboratory parameters in premenopausal women with and without hormonal contraception. Aktuel Endokrinol Stoffwechsel 8(3):142-149

26. Bosch B, Venter I, Stewart RI, Bertram SR (1990) Human chorionic gonadotrophin and weight loss. A double-blind, placebocontrolled trial. S Afr Med J 77(4):185-189

27. Boardman WW (1935) Rapidly developing cataracts after dinitrophenol. Cal West Med 43(2):118-119

28. McFee RB, Caraccio TR, McGuigan MA, Reynolds SA, Bellanger P (2004) Dying to be thin: a dinitrophenol related fatality. Vet Hum Toxicol 46(5):251-254

29. Miranda EJ, McIntyre IM, Parker DR, Gary RD, Logan BK (2006) Two deaths attributed to the use of 2,4-dinitrophenol. J Anal Toxicol 30(3):219-222

30. Grundlingh J, Dargan PI, El-Zanfaly M, Wood DM (2011) 2,4Dinitrophenol (DNP): a weight loss agent with significant acute toxicity and risk of death. J Med Toxicol 7(3):205-212

31. Bartlett J, Brunner M, Gough K (2010) Deliberate poisoning with dinitrophenol (DNP): an unlicensed weight loss pill. Emerg Med J 27(2):159-160

32. Siegmueller C, Narasimhaiah R (2010) "Fatal 2,4-dinitrophenol poisoning... coming to a hospital near you". Emerg Med J 27 (8):639-640

33. Yamamoto Y, Sogawa I, Nishina A et al (2000) Improved hypolipidemic effects of xanthan gum-galactomannan mixtures in rats. Biosci Biotechnol Biochem 64(10):2165-2171

34. Pittler MH, Ernst E (2001) Guar gum for body weight reduction: meta-analysis of randomized trials. Am J Med 110(9):724-730

35. Lewis JH (1992) Esophageal and small bowel obstruction from guar gum-containing "diet pills": analysis of 26 cases reported to the Food and Drug Administration. Am J Gastroenterol 87(10): $1424-1428$

36. Forman HP, Levin S, Stewart B, Patel M, Feinstein S (1989) Cerebral vasculitis and hemorrhage in an adolescent taking diet pills containing phenylpropanolamine: case report and review of literature. Pediatrics 83(5):737-741

37. Lake CR, Gallant S, Masson E, Miller P (1990) Adverse drug effects attributed to phenylpropanolamine: a review of 142 case reports. Am J Med 89(2):195-208

38. Kernan WN, Viscoli CM, Brass LM et al (2000) Phenylpropanolamine and the risk of hemorrhagic stroke. N Engl J Med 343 (25):1826-1832

39. Leo PJ, Hollander JE, Shih RD, Marcus SM (1996) Phenylpropanolamine and associated myocardial injury. Ann Emerg Med 28 (3):359-362

40. Pilsczek FH, Karcic AA, Freeman I (2003) Case report: dexatrim (phenylpropanolamine) as a cause of myocardial infarction. Heart Lung 32(2):100-104

41. Anon. Information by drug class $>$ phenylpropanolamine (PPA) information page. Available at: http://www.fda.gov/drugs/ drugsafety/informationbydrugclass/ucm150738.htm. Accessed October 31, 2011

42. Lee MR (2011) The history of ephedra (Ma-Huang). J R Coll Physicians Edinb 41(1):78-84

43. Abourashed EA, El-Alfy AT, Khan IA, Walker L (2003) Ephedra in perspective - a current review. Phytother Res 17(7):703-712 
44. Wiener I, Tilkian AG, Palazzolo M (1990) Coronary artery spasm and myocardial infarction in a patient with normal coronary arteries: temporal relationship to pseudoephedrine ingestion. Cathet Cardiovasc Diagn 20(1):51-53

45. Anon. $2004>$ FDA acts to remove Ephedra-containing dietary supplements from market. Available at: http://www.fda.gov/ NewsEvents/Newsroom/PressAnnouncements/2004/ucm108379. htm. Accessed October 13, 2011

46. Bruno A, Nolte KB, Chapin J (1993) Stroke associated with ephedrine use. Neurology 43(7):1313-1316

47. Haller CA, Benowitz NL (2000) Adverse cardiovascular and central nervous system events associated with dietary supplements containing ephedra alkaloids. N Engl J Med 343(25):1833-1838

48. Samenuk D, Link MS, Homoud MK et al (2002) Adverse cardiovascular events temporally associated with ma huang, an herbal source of ephedrine. Mayo Clin Proc 77(1):12-16

49. Anon. WEB_DAWN_089_HTML.pdf. Available at: http://www. samhsa.gov/data/2k11/WEB_DAWN_089/WEB_DAWN_089 HTML.pdf. Accessed December 30, 2011

50. Dietrich AM, Mortensen ME (1990) Presentation and management of an acute caffeine overdose. Pediatr Emerg Care 6(4):296-298

51. Kerrigan S, Lindsey T (2005) Fatal caffeine overdose: two case reports. Forensic Sci Int 153(1):67-69

52. Dalvi RR (1986) Acute and chronic toxicity of caffeine: a review. Vet Hum Toxicol 28(2):144-150

53. O’Donnell KA, Ewald MB (2009) Huffing and puffing to lose weight. Pediatr Emerg Care 25(9):605-607

54. Anon (2005) Atypical reactions associated with heroin use-five states, January-April 2005. MMWR Morb Mortal Wkly Rep 54 (32):793-796

55. Thompson JA, Mirza MH, Barker SA et al (2011) Clenbuterol toxicosis in three Quarter Horse racehorses after administration of a compounded product. J Am Vet Med Assoc 239(6):842-849

56. Daubert GP, Mabasa VH, Leung VWY, Aaron C (2007) Acute clenbuterol overdose resulting in supraventricular tachycardia and atrial fibrillation. J Med Toxicol 3(2):56-60

57. Hoffman RJ, Hoffman RS, Freyberg CL, Poppenga RH, Nelson LS (2001) Clenbuterol ingestion causing prolonged tachycardia, hypokalemia, and hypophosphatemia with confirmation by quantitative levels. J Toxicol Clin Toxicol 39(4):339-344

58. Connolly HM, Crary JL, McGoon MD et al (1997) Valvular heart disease associated with fenfluramine-phentermine. N Engl J Med 337(9):581-588

59. Teramae CY, Connolly HM, Grogan M, Jr Miller FA (2000) Diet drug-related cardiac valve disease: the Mayo Clinic echocardiographic laboratory experience. Mayo Clin Proc 75(5):456-461

60. Abenhaim L, Moride Y, Brenot F et al (1996) Appetite-suppressant drugs and the risk of primary pulmonary hypertension.
International Primary Pulmonary Hypertension Study Group. N Engl J Med 335(9):609-616

61. Weir EK, Huang JM et al (1996) Anorexic agents aminorex, fenfluramine, and dexfenfluramine inhibit potassium current in rat pulmonary vascular smooth muscle and cause pulmonary vasoconstriction. Circulation 94(9):2216-2220

62. Scheen AJ (2010) Cardiovascular risk-benefit profile of sibutramine. Am J Cardiovasc Drugs 10(5):321-334

63. Torp-Pedersen C, Coutinho W et al (2007) Cardiovascular responses to weight management and sibutramine in high-risk subjects: an analysis from the SCOUT trial. Eur Heart J 28(23):2915-2923

64. Perrio MJ, Wilton LV, Shakir SAW (2007) The safety profiles of orlistat and sibutramine: results of prescription-event monitoring studies in England. Obesity (Silver Spring) 15(11):2712-2722

65. James WPT, Caterson ID, Coutinho W et al (2010) Effect of sibutramine on cardiovascular outcomes in overweight and obese subjects. N Engl J Med 363(10):905-917

66. Akinyemi E, Bercovici S, Niranjan S, Paul N, Hemavathy B (2011) Thyrotoxic hypokalemic periodic paralysis due to dietary weight-loss supplement. Am J Ther 18(3):e81-e83

67. Chen YC, Fang JT, Chang CT, Chou HH (2001) Thyrotoxic periodic paralysis in a patient abusing thyroxine for weight reduction. Ren Fail 23(1):139-142

68. Diedrich DA, Wedel DJ (2006) Thyrotoxic periodic paralysis and anesthesia report of a case and literature review. J Clin Anesth 18 (4):286-292

69. Kaplan R (1998) Thyroxine abuse. Aust N Z J Psychiatry 32 (3):464-465

70. Hartung B, Schott M, Daldrup T, Ritz-Timme S (2010) Lethal thyroid storm after uncontrolled intake of liothyronine in order to lose weight. Int J Legal Med 124(6):637-640

71. Lau G, Chan CL (2002) Massive hepatocellular [correction of hepatocullular] necrosis: was it caused by Orlistat? Med Sci Law 42(4):309-312

72. Montero JL, Muntané J, Fraga E et al (2001) Orlistat associated subacute hepatic failure. J Hepatol 34(1):173

73. Finer N, James WP, Kopelman PG, Lean ME, Williams G (2000) One-year treatment of obesity: a randomized, double-blind, placebo-controlled, multicentre study of orlistat, a gastrointestinal lipase inhibitor. Int J Obes Relat Metab Disord 24(3):306-313

74. Engeli S, Böhnke J, Feldpausch M et al (2005) Activation of the peripheral endocannabinoid system in human obesity. Diabetes 54 (10):2838-2843

75. Pi-Sunyer FX, Aronne LJ, Heshmati HM, Devin J, Rosenstock J (2006) Effect of rimonabant, a cannabinoid-1 receptor blocker, on weight and cardiometabolic risk factors in overweight or obese patients: RIO-North America: a randomized controlled trial. JAMA 295(7):761-775 